\title{
ADULT ADHD MISTAKEN WITH BIPOLAR DISORDER ?
}

\author{
P. Sousa Martins ${ }^{1}$, J. Mota ${ }^{1}$ \\ ${ }^{1}$ Hospital de Magalhães Lemos - EPE, C Department, Porto, Portugal.
}

\section{INTRODUCTION}

Attention deficit hyperactivity disorder (ADHD) is a common chronic disorder characterized by inattention, hyperactivity and impulsivity. It is known that symptoms can persist into adulthood in up to $60 \%$ of patients. The first-line treatment is Methylphenidate. Although it can be mistaken for a manic episode, there are clear differences in presentation. The aim of this presentation is to raise awareness for the clinical similarity between adult ADHD and Bipolar Disorder and how this two disorders can be present on the same subject. Also, we want to highlight the importance of an accurate diagnosis and treatment.

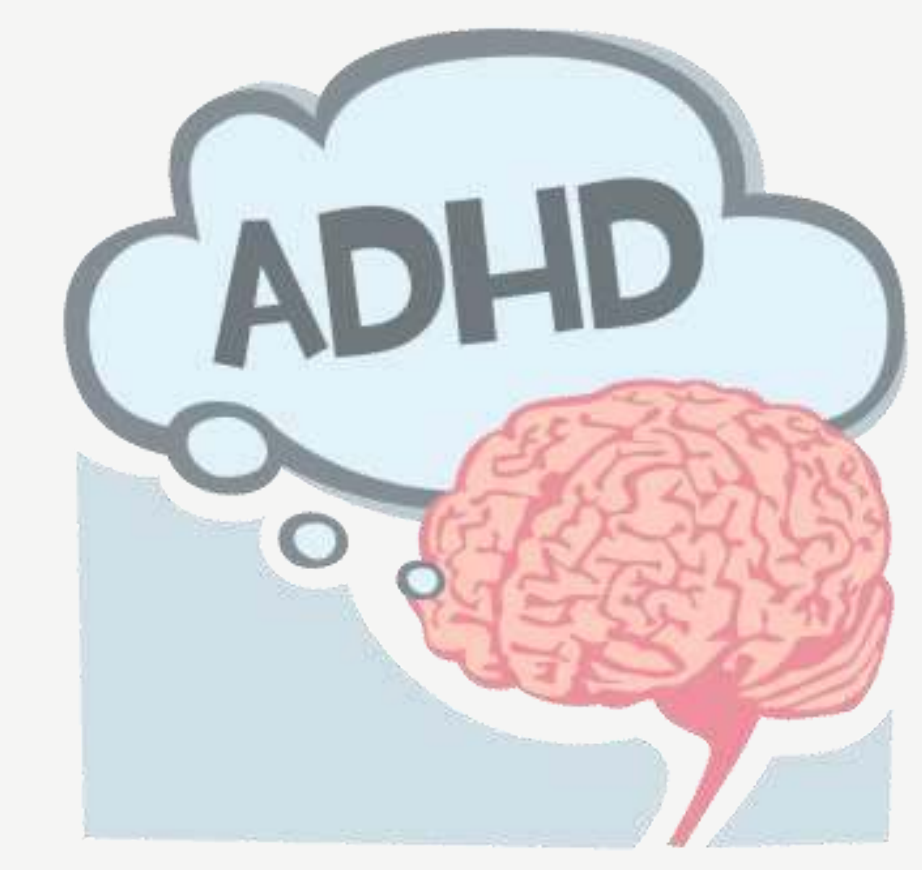

\section{CASE REPORT}

A man, aged 64, married and living with his wife, with a psychiatric history of ADHD was. At admission, it was reported that he was verborreic with pressure of speech, flight of ideas and delusion of grandeur. He had insight for his expansive mood even tough he told the attending psychiatric that he only lacked is usual medication: Methylphenidate, which he interrupted due to developing Essential Hypertension.

As this episode was compatible with a maniac episode and the patient was refusing to take any medication, he was involuntarily admitted to Hospital de Magalhães Lemos and treated with an antipsychotic. During his admission, his symptoms became aggravated, with disinhibition and psychomotor agitation and refusal to take the prescribed medication. After several days with no improvement in his symptoms, he interrupted antipsychotics and initiated Methylphenidate. An hasty remission of symptoms was observed, with discharge form the ward soon after. He has since attended follow up psychiatric appointments, with complete remission of symptoms.

\section{DISCUSSION}

Adult ADHD may lead to an erroneous diagnosis of Bipolar Disorder but the latter may be a comorbidity of the first. The rates of comorbidity of ADHD and Bipolar disorder are high - up to $20 \%$. Comorbid ADHD and Bipolar Disorder patients experience more severe mood episodes and more frequent affective episodes, earlier age of onset of Bipolar symptoms, more comorbid disorders, among other distinctive characteristics.

As a general rule, Bipolar disorder should be treated first. Second generation antipsychotics may reduce the efficacy of dopamine enhancing agents such as stimulants.

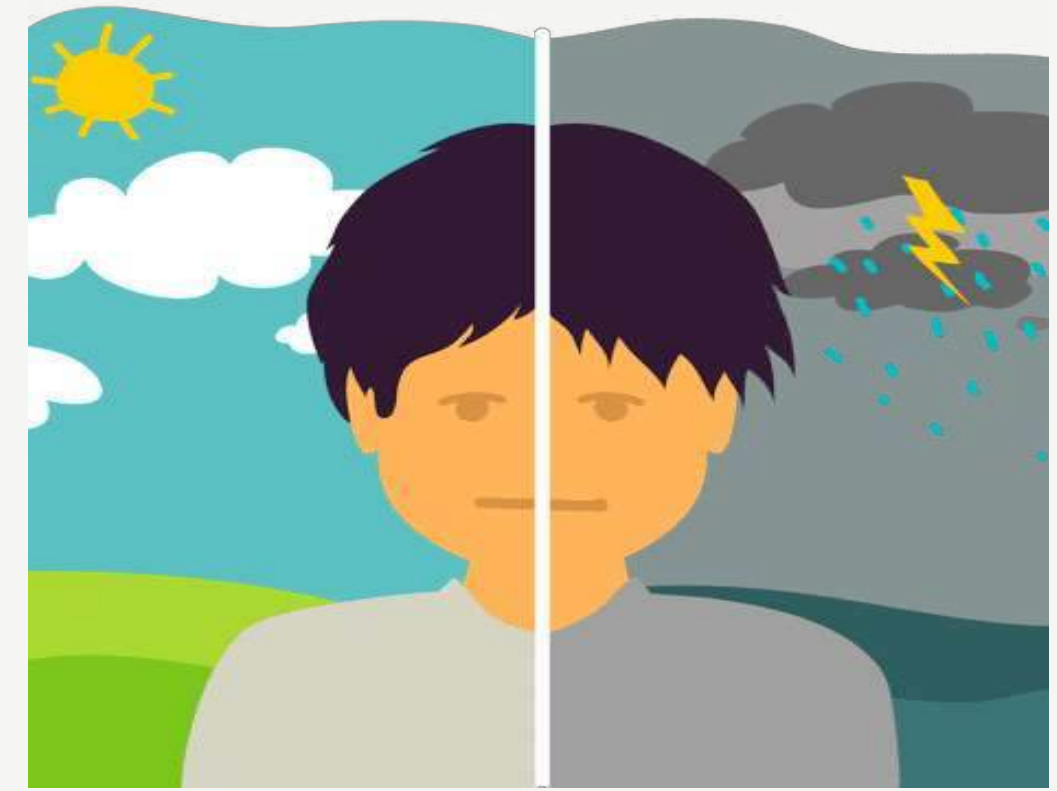

\section{CONCLUSION}

The patient had a complete remission of symptoms while being treated solely with methylphenidate which raises the probability of having a simple adult ADHD and no Bipolar Disorder, although the first choice of drugs was, in this case, understandable due to the symptoms the patient showed on admission.

More investigation on this theme is urgent to ultimately create guidelines on treating ADHD and its comorbidities

References: Sadek J. A Clinicians Guide to ADHD. Cham: Springer International Publishing; 2014. Sadek J. Clinician's Guide to Adult ADHD Comorbidities. Cham: Springer International Publishing; 2017. Brus MJ, Solanto MV, Goldberg JF. Adult ADHD vs. Bipolar Disorder in the DSM-5 Era. Journal of Psychiatric Practice. 2014;20:428-37. Katzman et al. Adult ADHD and comorbid disorders: clinical implications of a dimensional approach. BMC Psychiatry. 2017. 17:302. 